\title{
Phylogenetic position of gastrostomobdellid leeches (Hirudinida, Arhynchobdellida, Erpobdelliformes) and a new family for the genus Orobdella
}

\author{
Takafumi Nakano, Zainudin Ramlah \& Tsutomu Hikida
}

Submitted: 18 October 2011

Accepted: 24 November 2011

doi:10.1111/j.1463-6409.2011.00506.x

\begin{abstract}
Nakano, T., Ramlah, Z. \& Hikida, T. (2012). Phylogenetic position of gastrostomobdellid leeches (Hirudinida, Arhynchobdellida, Erpobdelliformes) and a new family for the genus Orobdella. -Zoologica Scripta, 41, 177-185.

The leech family Gastrostomobdellidae is characterized by its possession of an agnathous and euthylaematous pharynx, a ventral gastropore and a gastroporal duct. In this study, the phylogenetic position of two gastrostomobdellid genera, Gastrostomobdella and Orobdella, was investigated using partial nucleic 18S, $28 \mathrm{~S}$ rDNA and mitochondrial $12 \mathrm{~S}$ rDNA sequences. Our phylogenetic analyses showed that both Gastrostomobdella and Orobdella are nested within Erpobdelliformes, but Gastrostomobdellidae is not a monophyletic taxon. Orobdella is a sister taxon of the other Erpobdelliformes taxa. The phylogenetic position of Gastrostomobdella within the clade of Gastrostomobdella, Erpobdellidae and Salifidae still remains uncertain. According to the reconstruction of the ancestral state of the pharynx in Erpobdelliformes, a euthylaematous pharynx is considered to be plesiomorphic in this taxon. Examination of Gastrostomobdella and Orobdella specimens indicates that the morphology of the gastroporal duct of Orobdella is quite different from that of Gastrostomobdella. A new family, Orobdellidae fam. nov., was therefore erected for the genus Orobdella. Orobdellidae is characterized by its possession of a generally tubular gastroporal duct, lying on the female organ.

Corresponding author: Takafumi Nakano, Department of Zoology, Graduate School of Science, Kyoto University, Kyoto 606-8502, Japan.E-mail: nakano@zoo.zool.kyoto-u.ac.jp

Zainudin Ramlah, Department of Zoology, Faculty of Resource Science and Technology, Universiti Malaysia Sarawak, Kota Samarahan, Sarawak 94300, Malaysia. E-mail: zramlab@frst.unimas.my Tsutomu Hikida, Department of Zoology, Graduate School of Science, Kyoto University, Kyoto 606-8502, Japan. E-mail: tom@zoo.zool.kyoto-u.ac.jp
\end{abstract}

\section{Introduction}

The family Gastrostomobdellidae was originally established for two oriental terrestrial macrophagous leech genera, Gastrostomobdella Moore 1929 and Orobdella Oka 1895 (Richardson 1971). Later the genus Mimobdella Blanchard 1897 was placed in this taxon, and thus these three genera were considered to belong to Gastrostomobdellidae (Sawyer 1986). However, the internal anatomy of the type species, Mimobdella japonica Blanchard 1897, was not described in the original description (Blanchard 1897). More recent taxonomic work revealed that Mimobdella is not placed in Gastrostomobdellidae, but rather in Salifidae, because the holotype of Mi. japonica possesses salifid diagnostic characters, for example pharyngeal stylets (Nakano 2011a). Therefore, Gastrosto- mobdellidae now includes the original two genera, Gastrostomobdella and Orobdella.

The family Gastrostomobdellidae is diagnosed by an agnathous and euthylaematous pharynx, ventral gastopore and gastroporal duct (Richardson 1971). The type genus, Gastrostomobdella, consists of four species, which are distributed in South-east Asia and Hawaii (Moore 1929, 1935, 1946; Sawyer et al. 1982; Sawyer 1986). Leeches of this genus possess a columnar vertical gastroporal duct, and the canal of the duct is Y-shaped (Moore 1929, 1935, 1946). On the other hand, Orobdella includes eight species, which are distributed in East Asia (Oka 1895; Gilyarov et al. 1969; Richardson 1971, 1975; Lukin 1976; Nakano 2010, 2011b,c). Orobdella leeches are characterized by a generally tubular gastroporal duct and the duct lies on a 